TITLE:

Dynamic rupture analysis: Inversion
for the source process of the 1990
Izu-Oshima, Japan, earthquake (M
$=6.5$ )

$\operatorname{AUTHOR}(S):$

Fukuyama, Eiichi; Mikumo, Takeshi

CITATION:

Fukuyama, Eiichi ... [et al]. Dynamic rupture analysis: Inversion for the source process of the 1990 Izu-Oshima, Japan, earthquake (M =6.5). Journal of Geophysical Research: Solid Earth 1993, 98(B4): 6829-6542

ISSUE DATE:

1993-04-10

URL:

http://hdl.handle.net/2433/193399

RIGHT:

Copyright 1993 by the American Geophysical Union. 


\title{
Dynamic Rupture Analysis: Inversion for the Source Process of the 1990 Izu-Oshima, Japan, Earthquake $(M=6.5)$
}

\author{
EIICHI FUKUYAMA ${ }^{1}$
}

Laboratoire de Sismologie, Institut de Physique du Globe de Paris

\author{
TAKEShi Mikumo ${ }^{2}$
}

Disaster Prevention Research Institute, Kyoto University, Kyoto, Japan

\begin{abstract}
A waveform inversion has been applied to strong motion data using a dynamic shear crack model. We studied the 1990 Izu-Oshima earthquake $\left(M_{\text {JMA }}=6.5\right)$, which has vertical strike-slip faulting with unilateral rupture propagation. The inversion has two steps, a waveform inversion and a crack inversion, that are applied iteratively. A waveform inversion is used to determine the distribution of rupture starting times and slip dislocations using the slip functions calculated by the initial crack model, or by previous crack inversion. A crack inversion is used to calculate dynamic crack propagation that explains the results of the above inversion. In this step, we use the estimated rupture times as a locking fracture criterion; the maximum shear stress attained before a fault segment breaks gives a lower bound estimate of the peak shear strength at each fault segment. Then the dynamic stress drop distribution is estimated from the slip distribution obtained from waveform inversion assuming a dynamic crack model. From the results, we determine the rise time distribution and the distribution of a dimensionless stress ratio $S$ defined as (strength excess)/(stress drop). Our analysis gives the following picture of the rupture process of the 1990 Izu-Oshima earthquake: (1) An asperity-type faulting having large slip and high stress drop was detected in the region around the initiation point of rupture. (2) South of the asperity zone, barrier-type faulting characterized by incoherent propagating rupture, small slip, long rise time, and high strength excess was detected. This zone corresponds to the intersection of the fault with the 1978 earthquake $\left(M_{\mathrm{JMA}}=7.0\right.$ ).
\end{abstract}

\section{INTRODUCTION}

In the $1980 \mathrm{~s}$, a number of detailed earthquake source modeling studies have been made using waveform inversion techniques [Hartzell and Heaton, 1983; Ruff and Kanamori, 1983; Kikuchi and Fukao, 1985; Fukuyama and Irikura, 1986; Takeo, 1987; Beroza and Spudich, 1988: Kikuchi and Kanamori, 1991]. These studies are all based on "kinematic fault models" and do not involve "dynamic faulting mechanisms." In kinematic dislocation models, the form of the slip time function is prescribed arbitrarily by using a box-car, a triangle, or a trapezoidal shaped function. These arbitrary assumptions do not necessarily satisfy the stress-strain conditions on and around the fault. Accordingly, it is possible that the results obtained from waveform inversion based on the kinematic models may violate the stress-strain conditions and may even be physically unreasonable. To overcome these problems, we use dynamic shear crack model as a basis for the waveform inversion to the observed records. Mikumo et al. [1987] attempted to simulate the dynamic rupture process of a moderate size earthquake, fitting a kinematic model derived by waveform inversion by Takeo and Mikami [1987]. That was done by applying a threedimensional spontaneously fractured shear crack model in a horizontally layered structure under depth-dependent shear stress and laterally heterogeneous stress drop. Similarly,

\footnotetext{
${ }^{1}$ Permanently at National Research Institute for Earth Science and Disaster Prevention, Ibaraki, Japan.

${ }^{2}$ Now at Centro Nacional de Prevencion de Disastres, México.

Copyright 1993 by the American Geophysical Union.

Paper number 92JB02451.

0148-0227/93/92JB-02451\$05.00
}

Quin [1990] also attempted to interpret the source dynamic rupture history of the 1979 Imperial Valley earthquake. He tried to fit the source time function obtained from the strong motion records by Archuleta [1984] to a spontaneous rupture model calculated by a boundary integral method [Das, 1980]. He was successful in determining the general features of the stress-strength distribution over the fault. Miyatake [1992] presented a simpler method than that of Quin, which converts the distribution of kinematic parameters on a fault into that of dynamic parameters. However, since Quin and Miyatake did not recalculate the synthetic waveforms from the estimated rupture parameters, it is difficult to evaluate the degree of fit of their dynamic model to the recorded waveforms.

The main purpose of this paper is to estimate dynamic rupture properties of a moderate-size earthquake including the distributions of dynamic stress drop and shear strength excess from near-field seismograms. We take three steps: (1) calculate initial dynamic rupture of an earthquake assuming homogeneous distributions of the stress drop and strength excess over the fault based on the three-dimensional dynamic crack model, (2) perform a waveform inversion combined with the dynamic crack modeling in order to get the slip functions as well as the stress drop-strength excess distributions, and (3) estimate the distributions of rise time and dimensionless stress ratio $S$ using the above results. To confirm the validity of the above procedure, we also calculate the synthetic seismograms at each step and compare them with the observed records.

\section{The 1990 Izu-Oshima Earthquake}

The earthquake we study here is the 1990 Izu-Oshima earthquake $\left(M_{\mathrm{JMA}}=6.5\right)$, that occurred off the east coast of 
1990 Izu-Oshima earthquake

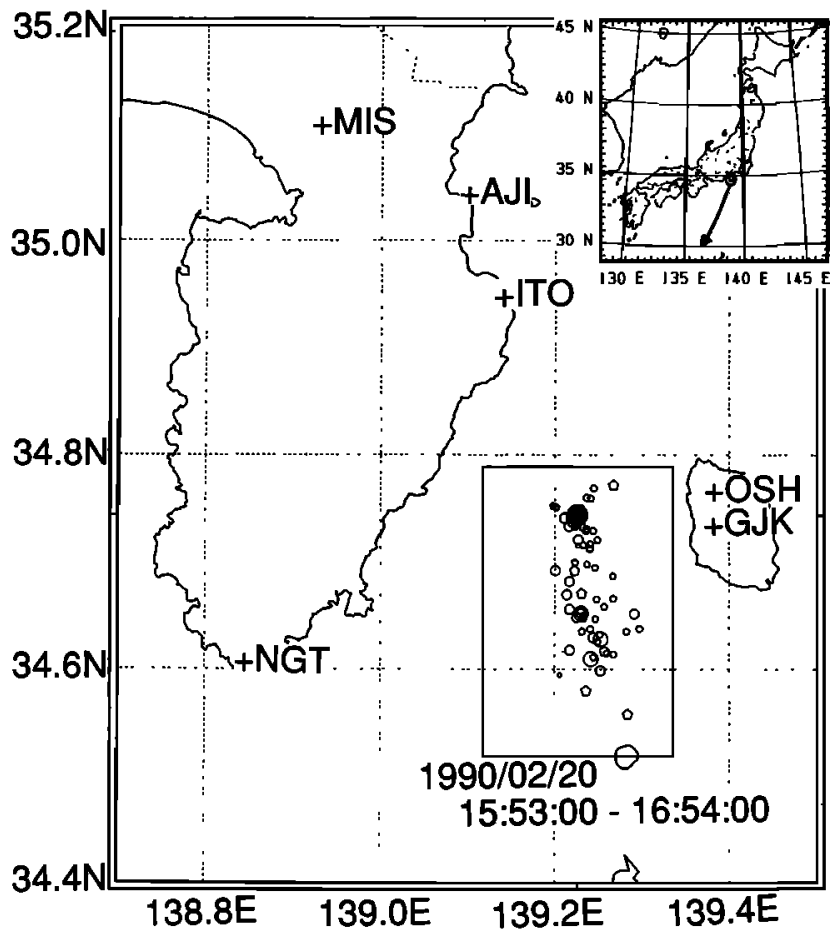

Fig. 1. Locations of the strong motion stations used in this analysis. Locations of the main shock epicenter (solid circle) and its aftershock distribution just after the main shock occurrence are also shown. The symbols for the aftershocks are classified by their magnitudes and depths (see Figure 19).

the Izu-Oshima island, central Japan. Although this is a tectonic earthquake, it seems to be related to the stress changes associated with the surrounding volcanic activities (1986-1987 Izu-Oshima eruption, 1989 Ito-Oki submarine volcano eruption, etc.). The fault of this earthquake is conjugate to the fault of the 1978 earthquake $\left(M_{\mathrm{JMA}}=\mathbf{7 . 0}\right)$ [Shimazaki and Somerville, 1979; Kikuchi and Sudo, 1984]. Figure 1 shows the epicenter of the 1990 Izu-Oshima earthquake (solid circle) and the distribution of its aftershocks that occurred within 1 hour after the main shock. The hypocenters of the main and aftershocks have been determined by the local microseismic network of the National Research Institute for Earth Science and Disaster Prevention (NIED). The strong motion observation sites we used are also indicated. Stations GJK and ITO belong to NIED, and AJI, MIS, NGT, and OSH belong to the Japan Meteorological Agency (JMA). The distance to the nearest station GJK is about $14 \mathrm{~km}$. Station GJK records ground velocity, while the other stations record ground accelerations. Figure 2 gives more details of spatial distribution of aftershocks, indicating that these earthquakes were distributed over a length of $19 \mathrm{~km}$ and at depths between $3 \mathrm{~km}$ and $17 \mathrm{~km}$. Focal mechanism solution from $P$ wave first motions is also shown indicating left-lateral strike-slip faulting along a nearly vertical plane. From the above evidence, we assume that the fault rupture initiated at the main shock hypocenter and spread unilaterally over a north-south striking vertical fault plane, as shown in Figure 3.

We estimate an average stress drop over the fault from the spectra of near-field seismograms. Figure 4 shows an example of three-component displacement waveforms derived from velocity seismograms at the nearest station GJK (Figure 1). We calculate the displacement spectrum of SH waves for all six stations. The time window used for this calculation is $10 \mathrm{~s}$, which is underlined in Figure 4. The obtained SH Fourier displacement spectrum for GJK is shown in Figure 5.

We estimate a seismic moment $M_{0}$ and a stress drop $\Delta \sigma$ from the flat level of the displacement spectrum $\Omega_{0}$ and its corner frequency $f_{c}$ using

$$
M_{0}=\frac{4 \pi \rho^{1 / 2}(\xi) \rho^{1 / 2}(x) \beta^{5 / 2}(\xi) \beta^{1 / 2}(x) R}{F^{S H}} \Omega_{0}
$$

[Aki and Richards, 1980], where $R$ is the distance from the source to the receiver and $F^{S H}$ is the radiation pattern of $S H$ waves, $x$ and $\xi$ are the receiver and the source locations, respectively, and

$$
\Delta \sigma=8.5 M_{0}\left[f_{c} / \beta\right]^{3}
$$

[Hanks and Wyss, 1972]. We assume that the density $\rho$ equals to $2.7 \times 10^{3} \mathrm{~kg} / \mathrm{m}^{3}$ for the source region and $2.3 \times 10^{3}$ $\mathrm{kg} / \mathrm{m}^{3}$ for the observation sites. The $S$ wave velocity $\beta$ has been taken as $3.5 \mathrm{~km} / \mathrm{s}$ for the source region and $1.7 \mathrm{~km} / \mathrm{s}$ for the observation sites. Table 1 shows the corner frequencies $f_{c}$, flat levels $\Omega_{0}$, moment releases $M_{0}$, and stress drops $\Delta \sigma$, which have been estimated from the records obtained at the six stations. We find that the average moment release is about $2.4 \times 10^{18} \mathrm{~N} \mathrm{~m}$ and the average stress drop is about 1.3 MPa. Although these are rough estimates, they remove a possible bias (an average of the stress drop) for the following inversion.

\section{InITIAL DyNamic MODEL}

As a starting model for the waveform inversion, we calculate the spatial and temporal patterns of spontaneous dynamic rupture propagation on the basis of a threedimensional dynamic shear crack model [Mikumo et al., 1987] with a homogeneous strength under a uniform shear stress. We incorporate a horizontally layered structure shown in Table 2, which has been obtained for this region from explosion seismic observations [Ikami, 1978; Takeo, 1988]. We did not take into account the shallowest thin low-velocity layer of Ikami [1978] and Takeo [1988] because of the discretized grid spacing of the crack calculation.

This calculation is made by solving numerically the wave equations for a three-dimensional space; using appropriate boundary conditions at the fault plane, at the free surface, and at each of the layer interfaces; and using an appropriate critical stress fracture criterion [Mikumo et al., 1987]. The fracture criterion we use here is approximately equivalent to the Irwin's [1958] criterion. If the critical average stress over the grid at the crack tip exceeds a certain limit (the static frictional strength in this case) at any point on the fault, a fault slip occurs immediately. This yields successive slips at adjacent segments and spontaneous rupture propagation on the fault [e.g., Mikumo et al., 1987]. The dynamic model thus specifies the form of the slip time function, the final slip, and the rupture time at each grid point.

Numerical calculations have been performed by finite differences. The dimension of the model space is $200 \mathrm{~km} \times$ $87 \mathrm{~km} \times 80 \mathrm{~km}$. We divide the entire fault surface into $19 \times$ 14 elements with a grid spacing of $1 \mathrm{~km}$. The time increment 
$1990 / 02 / 2015: 50-16: 54$
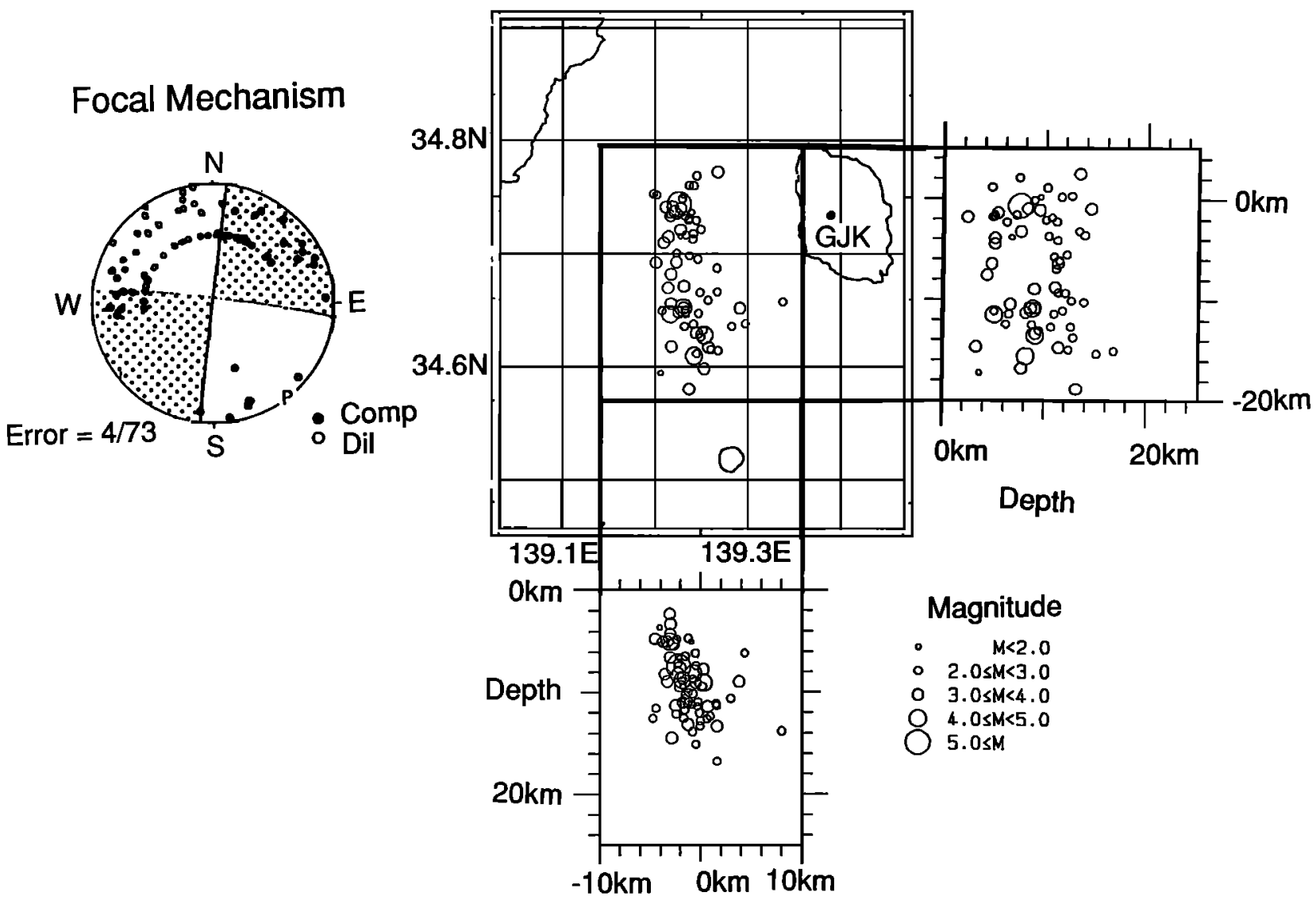

Fig. 2. Focal mechanism solution of the 1990 Izu-Oshima earthquake on the lower hemisphere projection (left). Aftershock distribution for 1 hour just after the main shock, which has been determined by the National Research Institute for Earth Science and Disaster Prevention, Japan (center), and its east-west cross section (center lower) and its north-south cross section (right). The location of the main shock is indicated as the largest circle.

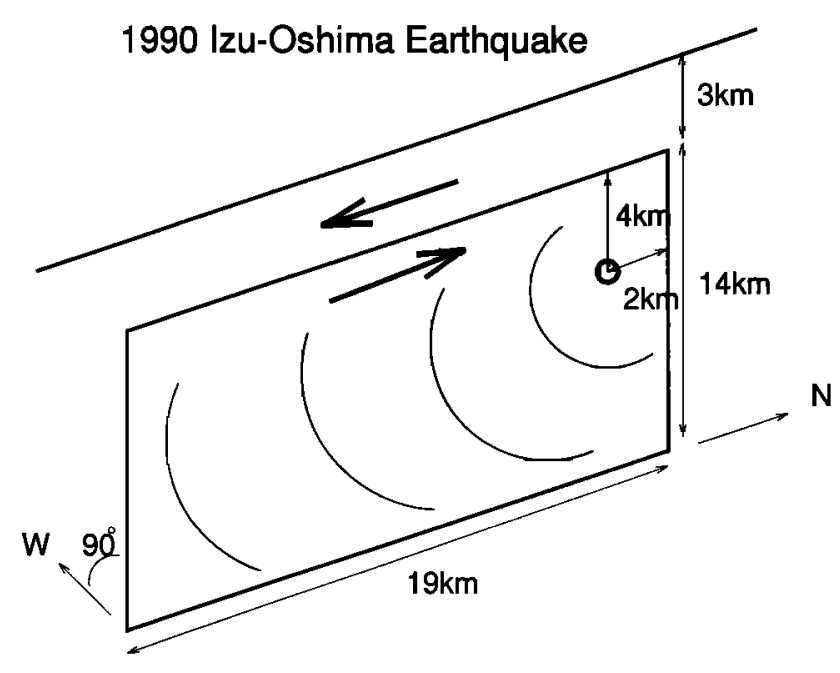

Fig. 3. A schematic fault model of the 1990 lzu-Oshima earthquake. The initiation point of rupture is assumed to be located at the hypocenter of the main shock $\left(34.744^{\circ} \mathrm{N}, 139.226^{\circ} \mathrm{E}, 7.4 \mathrm{~km}\right)$.
1990 Izu-Oshima Earthquake
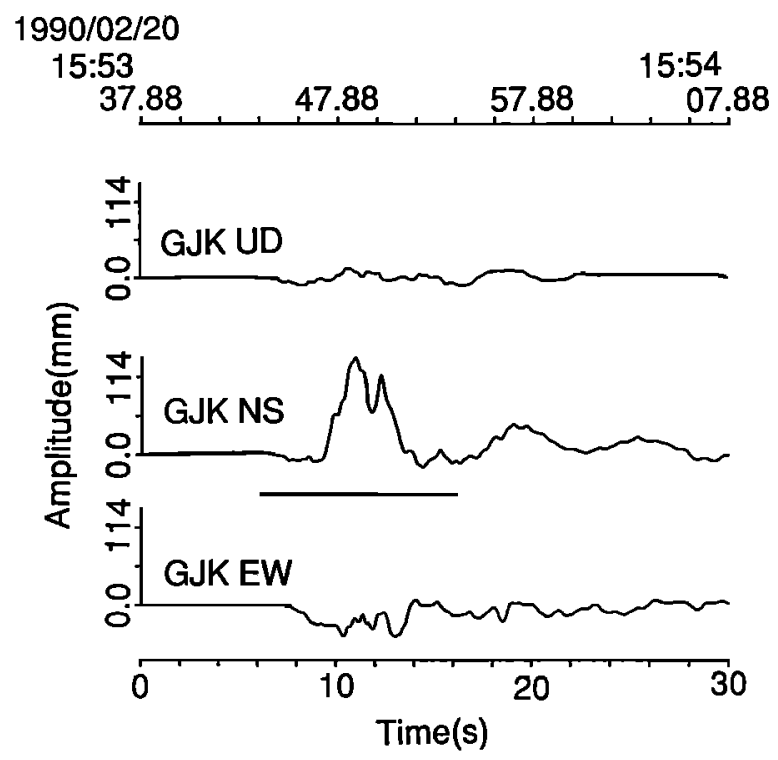

Fig. 4. Three-component displacement waveforms obtained from the observed velocity seismogram at GJK. The time windows for the spectrum analysis are indicated by underlining. 


\section{SH Displacement Spectrum at GJK}

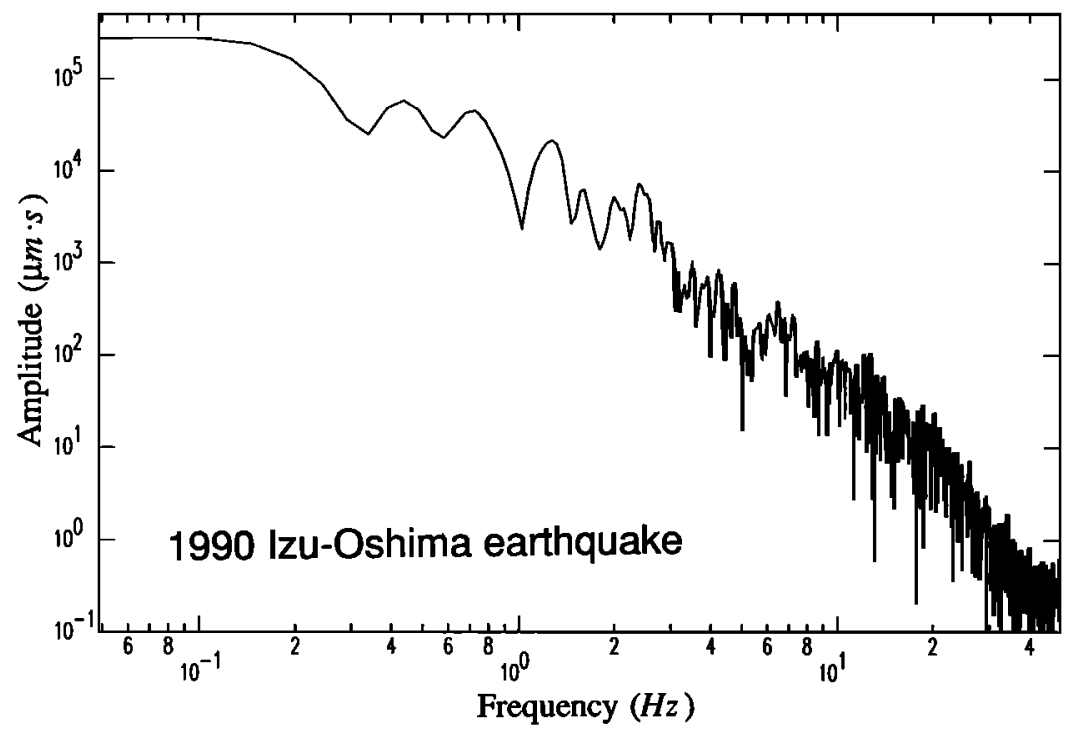

Fig. 5. Fourier amplitude spectrum of the 1990 Izu-Oshima earthquake. The north-south component displacement waveforms obtained at GJK is used for this calculation.

is $0.05 \mathrm{~s}$. These values satisfy the stability condition for the wave equation in the three-dimensional space.

In dynamic crack models, the patterns of dynamic rupture propagation and slip distribution are governed by the dynamic stress drop $\sigma_{0}-\sigma_{d}$ and the strength excess $\sigma_{s}-\sigma_{0}$, where $\sigma_{0}, \sigma_{s}$, and $\sigma_{d}$ are the initial shear stress, the static frictional strength (or the peak shear stress), and the sliding frictional stress, respectively. Here we assume these parameters to be $20.0,20.25$, and $18.5 \mathrm{MPa}$, respectively, which give a uniform strength excess of $0.25 \mathrm{MPa}$ and a uniform stress drop of $1.5 \mathrm{MPa}$. The stress drop of $1.5 \mathrm{MPa}$ is inferred from the displacement spectrum of $\mathrm{SH}$ waves.

The stress drop affects the amount of slip. On the other hand, the strength excess specifies the pattern of rupture propagation. When the strength excess is small, the rupture propagates with a $\boldsymbol{P}$ wave velocity in the direction parallel to the applied stress and with a $S$ wave velocity in the direction perpendicular to it [see Mikumo and Miyatake, 1978; Miyatake, 1980; Mikumo et al., 1987]. When the strength excess is high enough, the rupture has slower initial velocities or may not initiate at all. Figure 6 shows a perspective view of rupture propagation and fault slips at every time step. The slightly larger slips in the southern section are due to the unilateral rupture propagation. A unilateral rupture causes a

TABLE 1. Moments and Stress Drops Estimated by Spectral Analysis

\begin{tabular}{ccccc}
\hline & & & $\begin{array}{c}M_{0}, \\
\times 10^{18} \mathrm{~N} \mathrm{~m}\end{array}$ & $\begin{array}{c}\Delta \sigma, \\
\mathrm{MPa}\end{array}$ \\
\hline Station & & & & \\
GJK & 0.141 & 0.142 & 2.41 & 1.34 \\
OSH & 0.145 & 0.148 & 2.41 & 1.46 \\
ITO & 0.145 & 0.061 & 1.96 & 1.19 \\
AJI & 0.129 & 0.050 & 2.36 & 1.00 \\
NGT & 0.129 & 0.085 & 3.04 & 1.29 \\
MIS & 0.145 & 0.037 & 2.43 & 1.29 \\
Average & & & 2.43 & 1.29 \\
\hline
\end{tabular}

concentration of seismic energy ahead of the rupture front that produce the large slip; such asymmetrical slip distribution should occur even on a fault with a uniform strength and subjected to a uniform stress. Similar numerical calculation shows that the final slip is symmetrically distributed when the rupture starts at the center of the fault, as expected.

Figure 7 shows the distributions of the arrival time of rupture front and final amount of slip on the fault for the initial model. For this model, the distributions of rupture time and displacement are relatively smooth. Figure 8 shows a comparison between the observed waveforms (solid lines) and the corresponding synthetic waveforms (dashed lines). The waveforms have been normalized by the larger of the peak amplitude in both trace. This normalizing factor is shown at the upper right of each trace in millimeters. The agreement between these two sets of waveforms is not satisfactory. Total moment release from the initial model is $4.6 \times 10^{18} \mathrm{~N} \mathrm{~m}$. Although this value is about 2 times larger than that estimated by the spectral analysis, since the peak amplitudes are almost coincides with each other, we take this model as an initial one. From these calculations, we obtain the slip time functions at each grid of the fault surface and use them as a starting model for the following inversion.

\section{ITERATIVE INVERSION METHOD}

The iterative inversion presented here consists of a waveform inversion and a crack inversion. The waveform inver-

TABLE 2. Velocity Structure for Dynamic Crack Model

\begin{tabular}{rccc}
\hline $\begin{array}{c}\text { Depth, } \\
\mathrm{km}\end{array}$ & $\begin{array}{c}V_{P}, \\
\mathrm{~km} / \mathrm{s}\end{array}$ & $\begin{array}{c}V_{S}, \\
\mathrm{~km} / \mathrm{s}\end{array}$ & $\begin{array}{c}\rho, \\
\mathrm{g} / \mathrm{cm}^{3}\end{array}$ \\
\hline 0.0 & 4.6 & 2.66 & 2.5 \\
2.0 & 6.0 & 3.46 & 2.7 \\
15.0 & 6.8 & 3.93 & 3.0 \\
29.7 & 7.8 & 4.50 & 3.2 \\
\hline
\end{tabular}



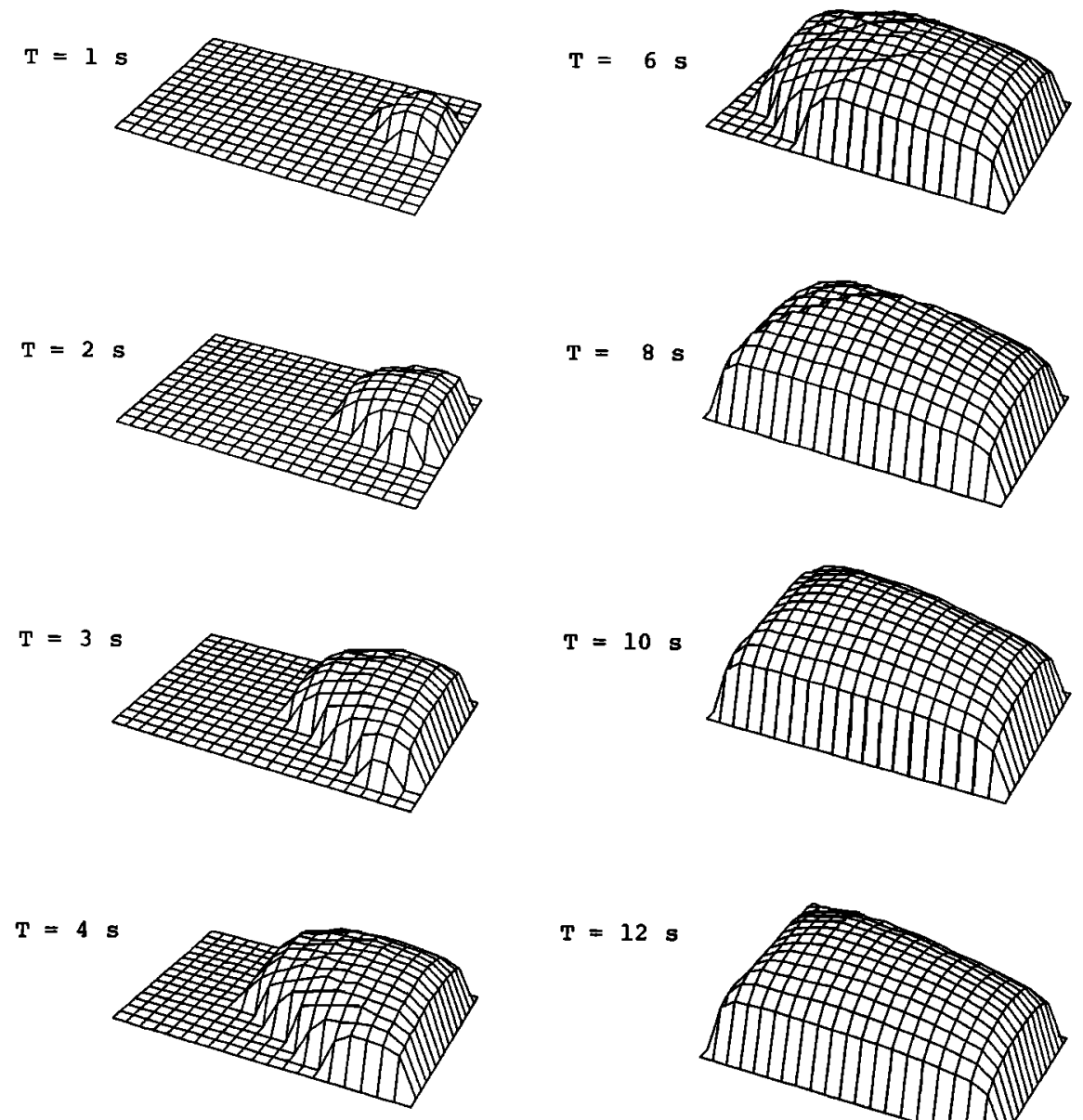

$T=12 \mathrm{~s}$
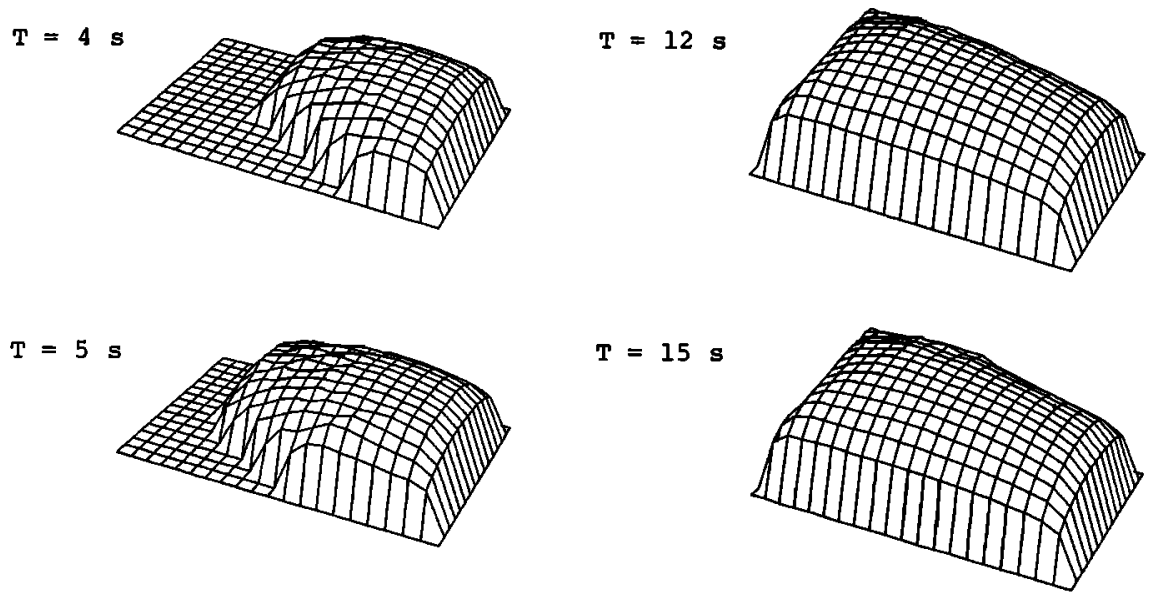

Dynamic Rupture ( Starting Model )

Fig. 6. Displacement history over the fault surface calculated from an initial dynamic rupture model with a homogeneous stress drop and strength excess.

sion gives us the distribution of rupture times and slip dislocations by inverting the observed waveforms with a fixed form of slip function. The crack inversion is used to invert the kinematic parameters obtained in the previous step, giving us the distribution of stress drops and strength excesses as well as the shape of the slip time function. We repeat these two inversions by turns until the residual between the observed and synthetic waveforms becomes satisfactorily small. Figure 9 shows an example of an improvement process of slip functions at particular points of the fault. Through the iteration, the shape of the source time function changes gradually as the fit to the data improves.

\section{Waveform Inversion}

We calculate the Green's functions for all combinations of fault segments and stations assuming the horizontally layered structure shown in Table 3 (same as the "velocity structure 1" of Takeo [1988]). The Green's functions are calculated by a discrete wavenumber method [Bouchon, 1981; Yao and Harkrider, 1983]. Dissipative effect are accounted for by introducing complex wave velocities. Examples of the Green's functions for some fault segments at station NGT are shown in Figure 10. We calculate synthetic seismograms by convolving these Green's functions with the 


\section{a) Rupture Time}

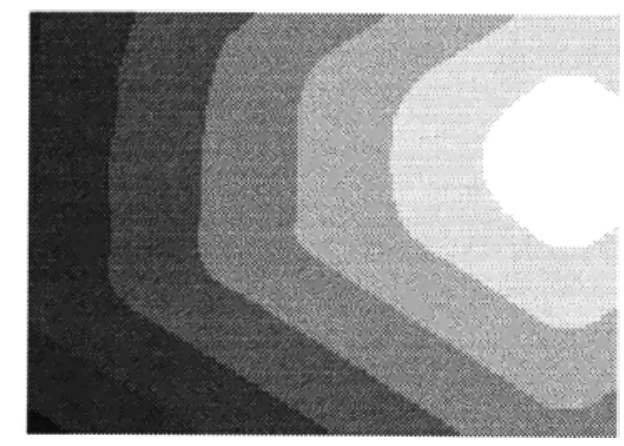

South

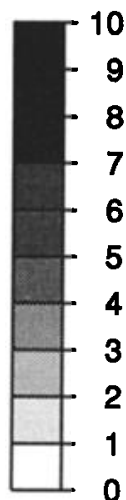

North b) Slip Dislocation

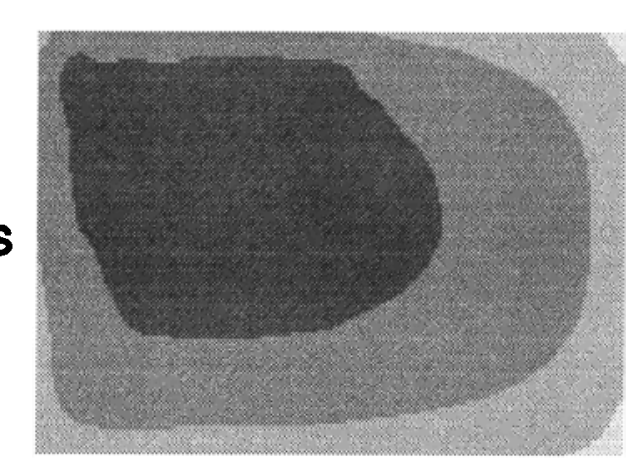

South

Fig. 7. Initial parameter distributions of $(a)$ rupture time and $(b)$ dislocation over the fault. The parameters are extracted from the slip time functions calculated from the homogeneous dynamic model.

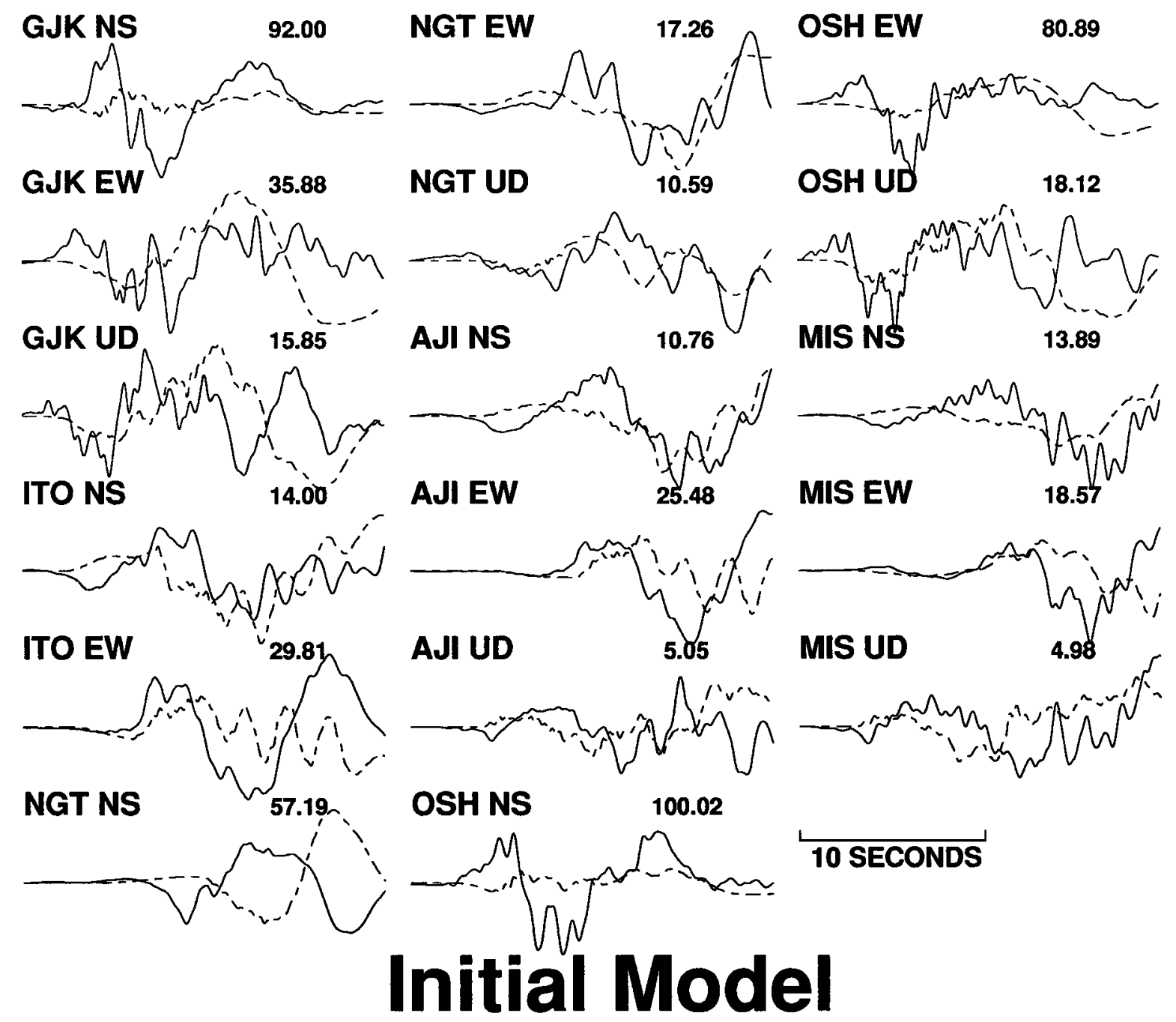

Fig. 8. A comparison between the observed seismograms (solid lines) and the synthetic waveforms (dashed lines) calculated from the initial model. Both traces are drawn in the same scale in each window. The numerals attached to each trace indicates the maximum amplitude in millimeters. The same explanations apply to Figures 16 and 19. 

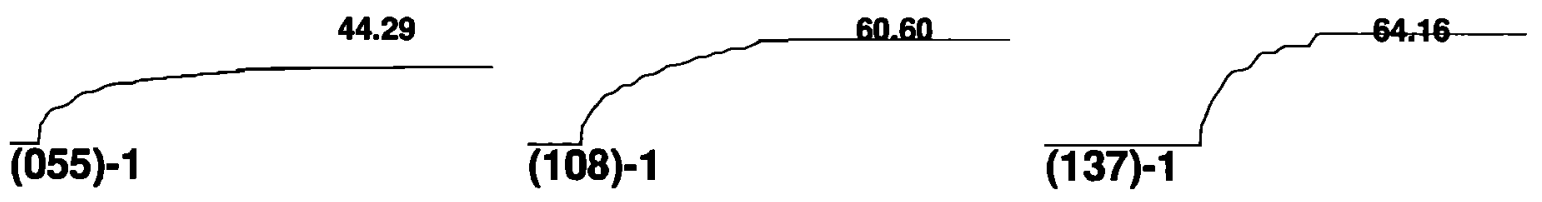

61.22
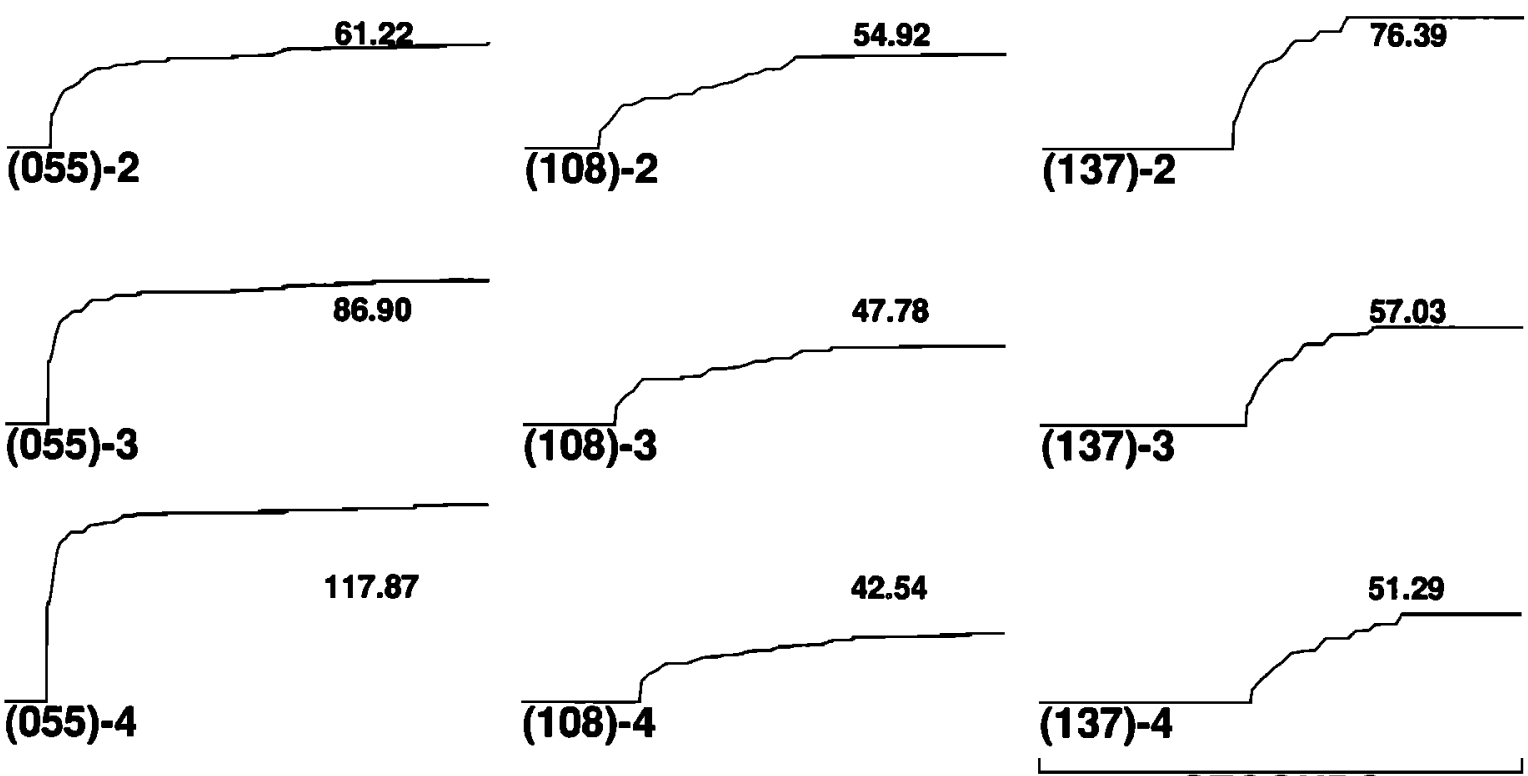

15 SECONDS

\section{Progress of Source Time Functions}

Fig. 9. Some examples of slip time functions during the iterative inversion. Numerals inside the parentheses indicate the location of grid that will appear in Figure 11. Numerals followed by a minus sign show the iteration steps (" 1 " indicates the initial model). (Left) The largest asperity region, (center) the barrier region, and (right) the second largest asperity region.

corresponding slip time functions and by integrating them over the entire fault surface. The sampling interval of synthetic seismograms and Green's functions is $0.025 \mathrm{~s}$.

In order to reduce the number of parameters to be estimated in the waveform inversion scheme, we divide the entire fault into 25 subfaults (Figure 11), each of which includes 6 to 12 unit segments with a dimension of $1 \mathrm{~km} \times 1$ $\mathrm{km}$. In each subfault we assume that the deviation of rupture time and slip dislocation is the same. This reduces the number of parameters from $266 \times 2$ to $25 \times 2$. To save the computation time, we also assume that all segments belonging to the same subfault have the same the Green's function.

The relation between the parameters estimated by the waveform inversion and those inverted by the crack inversion is shown in (3) and (4):

TABLE 3. Velocity Structure for Green's Function

\begin{tabular}{ccccrr}
\hline $\begin{array}{c}\text { Depth, } \\
\mathrm{km}\end{array}$ & $\begin{array}{c}V_{P}, \\
\mathrm{~km} / \mathrm{s}\end{array}$ & $\begin{array}{c}V_{S}, \\
\mathrm{~km} / \mathrm{s}\end{array}$ & $\begin{array}{c}\rho, \\
\mathrm{g} / \mathrm{cm}^{3}\end{array}$ & $Q_{P}$ & $Q_{S}$ \\
\hline 0.0 & 3.0 & 1.73 & 2.3 & 80 & 40 \\
1.0 & 4.6 & 2.66 & 2.5 & 200 & 100 \\
4.3 & 6.0 & 3.46 & 2.7 & 300 & 150 \\
15.0 & 6.8 & 3.93 & 3.0 & 500 & 250 \\
29.7 & 7.8 & 4.50 & 3.2 & 1000 & 500 \\
\hline
\end{tabular}

$$
\begin{gathered}
t_{0 i}^{k+1}=t_{0 i}^{k}+\Delta t_{0 j} \\
d_{i}^{k+1}=d_{i}^{k} \times\left(1+\Delta d_{j}\right)
\end{gathered}
$$

where, $t_{0 i}^{k}$ and $d_{i}^{k}$ represent the rupture time and slip at $i$ th grid in the $k$ th iteration cycle, respectively. $\Delta t_{0 j}$ and $\Delta d_{j}$ are parameters of the $j$ th subfault estimated by the waveform inversion. Here, $i$ takes on values from 1 to 266 , and $j$ is from 1 to 25 .

For waveform inversion we use the method by Fukuyama [1991a] which determines the model parameters by iteratively minimizing the difference between the observed and the synthetic waveforms. For the data, we use threecomponent displacements at six near-field stations (Figure 1) which are converted from the observed velocity seismograms or accelerograms by numerical integration. They are then filtered in the period range from 20 to $0.5 \mathrm{~s}$ in order to reduce the high-frequency waves which cannot be produced by the Green's function. We do not use the UD component record at ITO due to a poor quality of the waveforms caused by an electrical trouble during the observation. We set the variance of data as 20.0 [ $\mathrm{mm}^{2}$ ] and the variances of parameters $\Delta t_{0}$, and $\Delta d$ are changed from 0.01 to $0.2\left[\mathrm{~s}^{2}\right]$ and from 0.005 to 0.1 , respectively. These variances of the parameters are chosen in order to obtain the best convergence of inversion. From all seismograms the data are extracted in 
25.42

03 NS Hothor

51.22

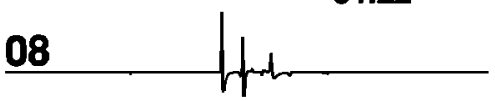

72.51

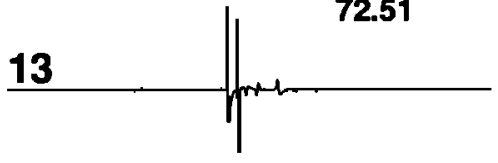

84.44

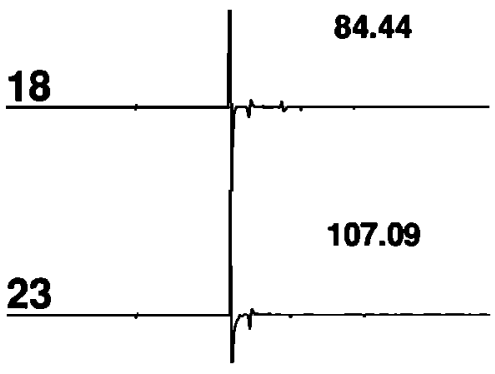

$-6.41$

03 EW

$-12.22$

08

13

14.55

18

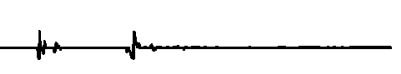

$-30.58$

23
O3 UD

12.69

08

13

$-23.99$

18

24.34

Fig. 10. Examples of the calculated Green's functions at NGT for the subfaults 03, 08, 13, 18, and 23 that will appear in Figure 11. These functions have been calculated by a discrete wavenumber method.

19.5-s time windows starting about $5 \mathrm{~s}$ preceding the $P$ arrivals. The data include all the near-field body waves.

The resolution of the estimated parameters is investigated using synthetic data obtained by the final parameters [Fukuyama, 1991b]. If all parameters are estimated correctly, the resolution of parameters is perfect. Otherwise, the difference between the real and simulated inversion results reflects the trade-off between these parameters.

\section{Crack Inversion}

In this inversion, we estimate the distribution of dynamic stress drop and strength excess over the fault plane that are consistent with the results of the waveform inversion. To do this, we recalculate the spontaneous dynamic rupture process so as to satisfy the previously estimated kinematic fault parameters, i.e., the distribution of the fault slip and rupture time. These two parameters have been estimated for each of the 25 divided subfaults; before they are inverted using crack

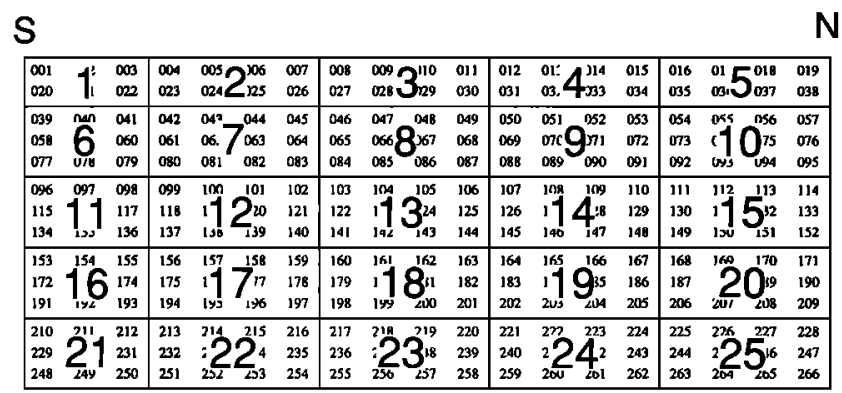

Fig. 11. Fault segmentation into 25 subfaults from $2661-\mathrm{km}^{-}$ spacing grids. inversion, they are smoothed over the fault plane and spatially interpolated at grid points with a spacing of $1 \mathrm{~km}$. Applying equations (3) and (4), we obtain the distribution of parameters on 266 grid points.

The first step is to fix the rupture time at each grid point to that obtained from the waveform inversion. This is equivalent to introducing a locking fracture criterion, under which a fault element does not break before the specified rupture time. We assume that the rupture is locked for some time depending on the fault strength located ahead of the advancing crack tip. The stress at the locked segment increases from the initial level up to the time when it fails. The peak shear strength can then be estimated from the maximum shear stress just before the segment breaks. This procedure follows that of Miyatake [1992] and is similar in a sense to that adopted by Quin [1990]. Although the peak strength estimated in this way depends on the grid spacing used in the numerical calculations, it should be regarded as a lower bound of the real peak strength. For the fixed rupture times, the final slips depend only on the dynamic stress drop [Quin, 1990].

The second step is to estimate the distribution of dynamic stress drop from the fault slip obtained by the waveform inversion. The dynamic rupture propagation is determined by assigning different stress drops on each of the subfaults and by comparing the resultant dynamic slip with the slip from the waveform inversion. The initially assigned stress drops are then multiplied by ratio between the two types of the slip averaged within each of the subfaults. This procedure is repeated until the square sum of the difference between the dynamic and kinematic slips is minimized. Since the above procedure involves nonlinear effects inter- 
a) Rupture Time

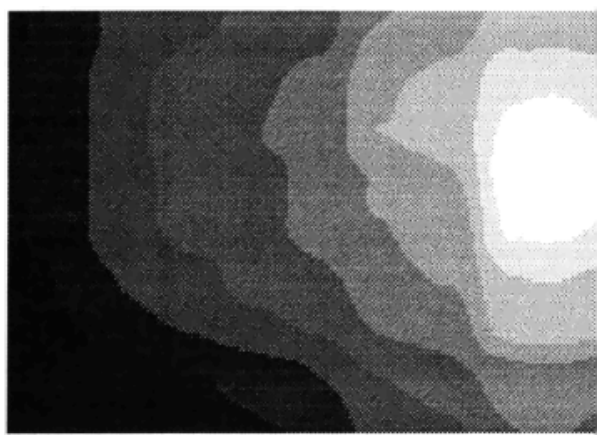

South

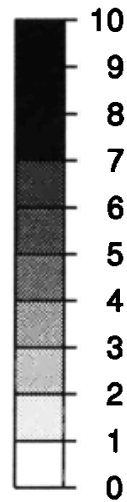

North b) Slip Dislocation

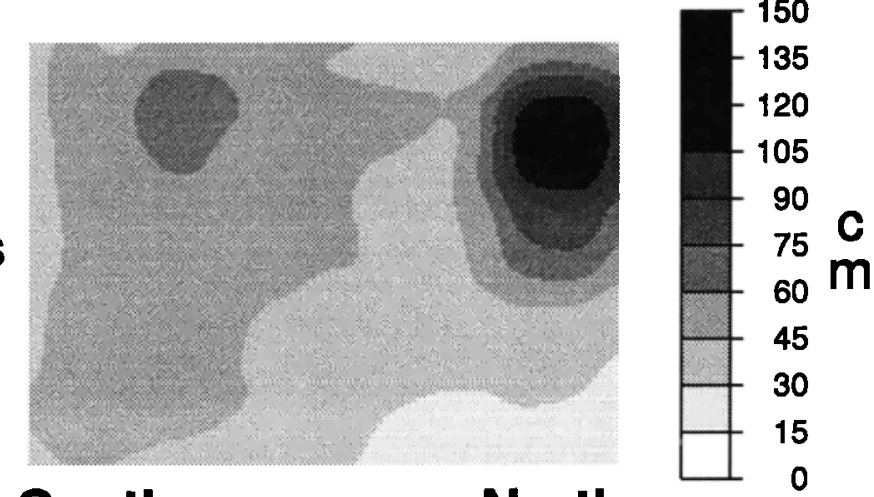

South
North

Fig. 12. Final crack inversion solution (modelC3-01), (a) rupture time, and (b) dislocation. The results are shown by their absolute values, which are the sum of their initial values and the deviations obtained by the waveform inversion.

acting between dynamic slips at adjacent fault segments, several repeated calculations are needed to obtain a best fit.

The slip time functions obtained here are then fed back into the subsequent waveform inversion in the revised model.

\section{RESULTS OF ITERATIVE INVERSION}

After four iteration cycles, inverting from 5 to 20 trials of the waveform inversion and the crack inversion, we have reached the preferred solution named model C3-01. The residual reduction is about $40 \%$ with respect to the initial model. In Figure 12, we show the distributions of final parameters over the fault. The total moment release is $4.0 \times$ $10^{18} \mathrm{~N} \mathrm{~m}$. Taking into account the resolution of parameters during the waveform inversion (Figure 13), the following features can be seen: (1) The rupture propagated incoherently at the initial stage, and its velocity was slow in the region about $5 \mathrm{~km}$ south of the northern fault edge. (2) The largest slip $(\sim 130 \mathrm{~cm})$ was observed in a narrow region near the initiation point, and the second largest slip $(\sim 60 \mathrm{~cm})$ at the southern part of the fault.

The slip time function at each grid has been calculated from the final dynamic rupture model. Several examples of the slip time functions are shown in Figure 9. From these slip functions, we calculate the rise times which are defined as the time until the slip reaches $95 \%$ of the final slip. Figure 14 shows the spatial distribution of the estimated rise times. It is noticed that the rise times range from less than $2 \mathrm{~s}$ (at the bottom of the fault) to more than $10 \mathrm{~s}$ (at the zone south of the hypocenter). The average rise time is about $7 \mathrm{~s}$.

Figure 15 shows a comparison between the observed and synthetic waveforms calculated for the final model. The agreement between the two waveforms has considerably improved compared to the initial model, but some discrepancy still remains. The disagreement may be due to the complex crustal structure in the Izu region, where the Philippine Sea plate collides against the Eurasian plate and subducts both eastward and westward. Our crustal model does not take into account such lateral heterogeneity (Tables 2 and 3 ).

Figure 16 shows a time-sliced perspective view of the rupture propagation of the fault slip over the fault plane. We see the incoherent propagation of rupture and heterogeneous distribution of the fault slips. The rupture initiates with large

\section{a) Rupture Time}

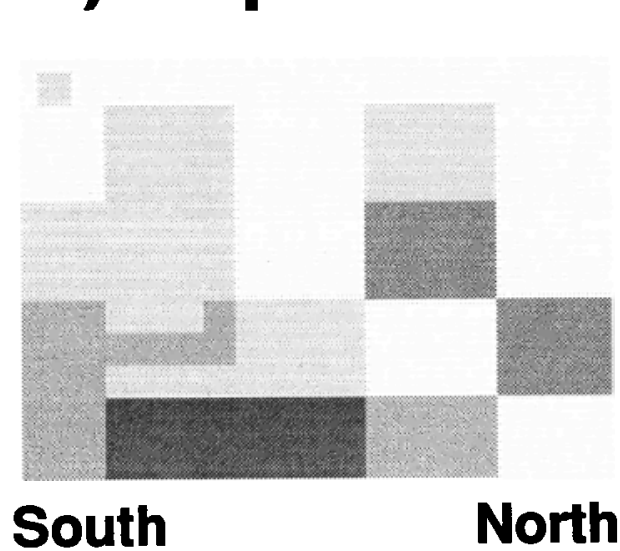

\section{b) Slip Dislocation}

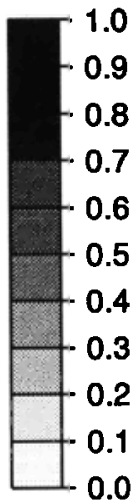

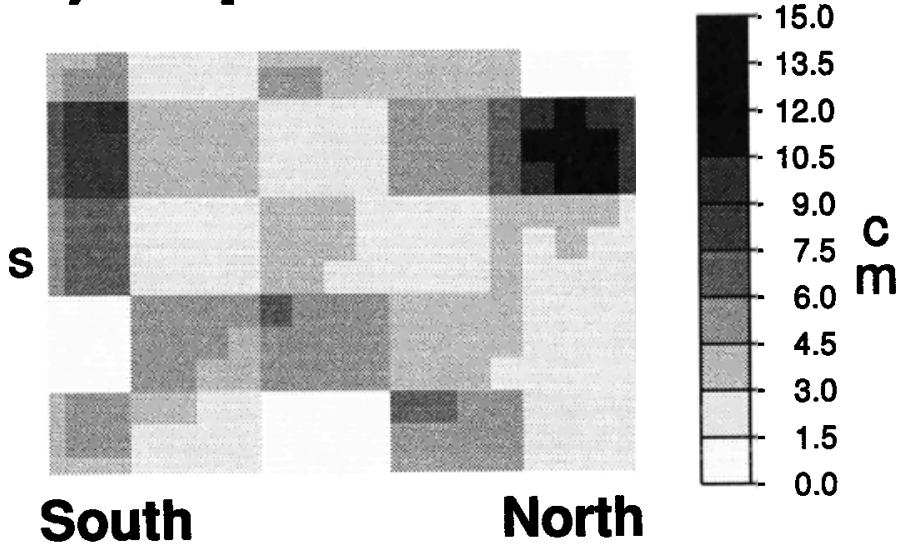

Fig. 13. Error estimates for each parameters. The method for the estimate follows Fukuyama [1991b] (see text). 


\section{a) Initial Model}

\section{b) Model \#C3-01}
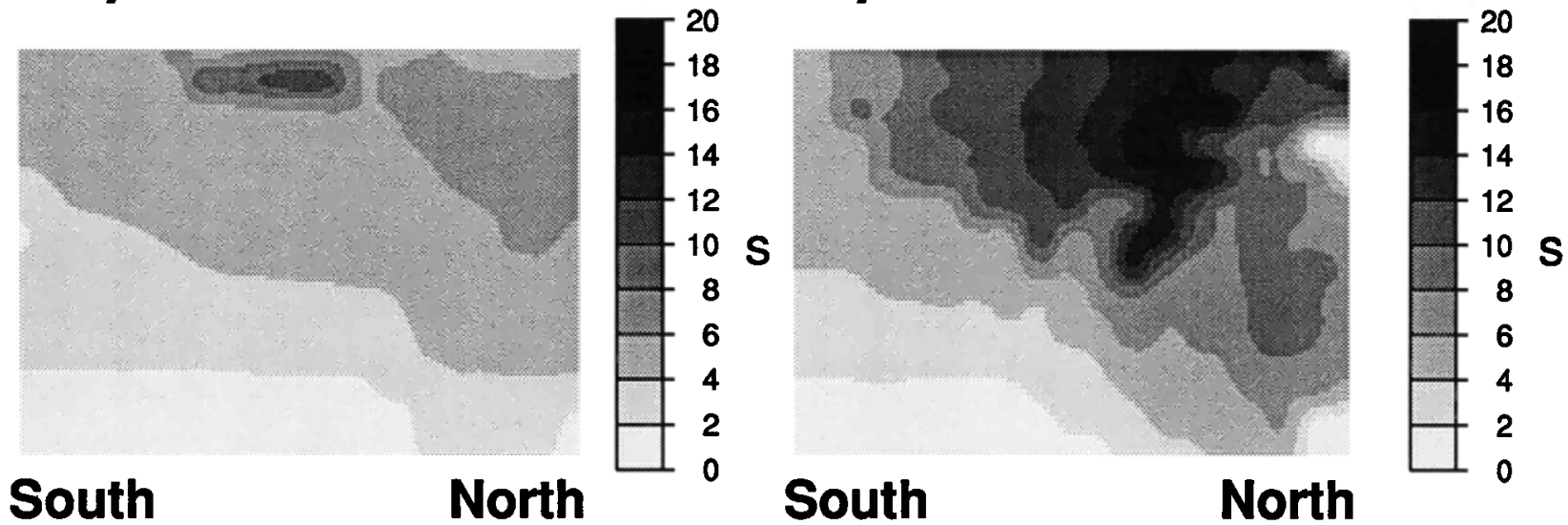

Fig. 14. Rise time distribution of the initial model and the final model (C3-01).

slips, spreading slowly in the first $3 \mathrm{~s}$. After this time, it propagates nearly unilaterally southward, taking longer to break the deeper section of the fault. The major rupture process lasts about $10 \mathrm{~s}$. The large slip around the rupture initiation zone continues to grow up to about $8 \mathrm{~s}$.
Distributions of Dynamic Stress Drop aND STRENGTH ExcESS

Figure 17 shows the distribution of the dynamic stress drop and strength excess over the fault plane. The probable

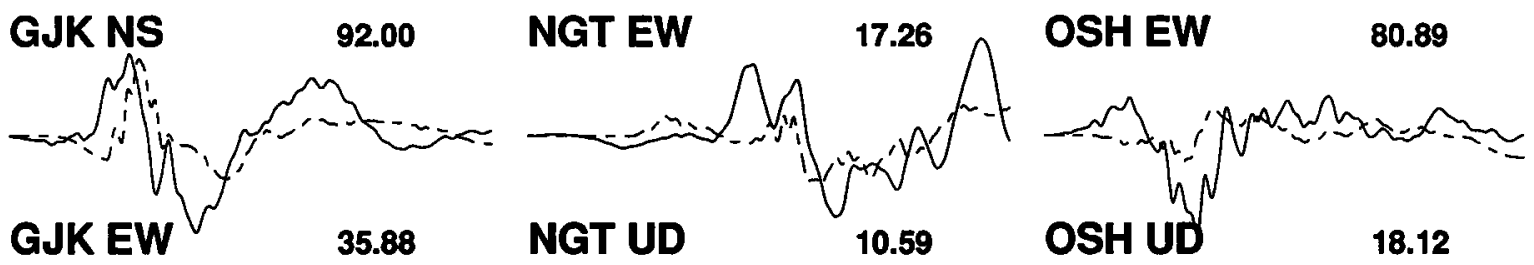

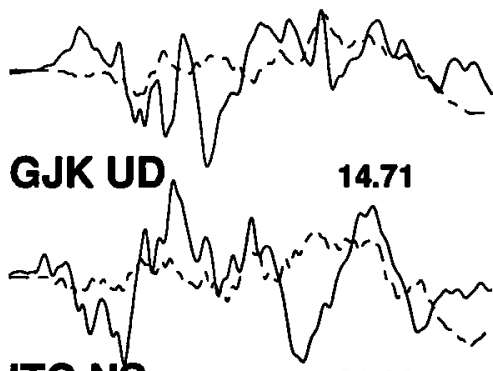

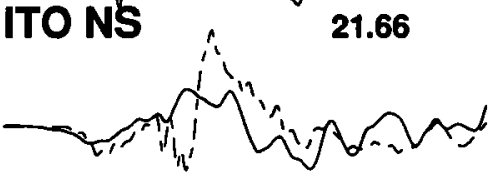

ITO EW

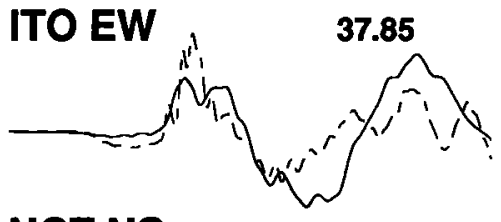

NGT NS

39.77

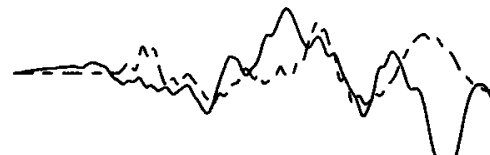

AJl NS

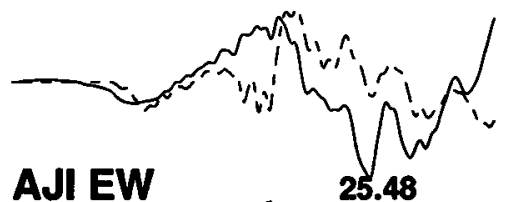

AJI EW

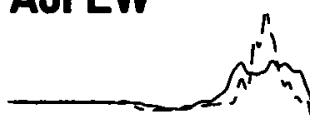

AJI UD

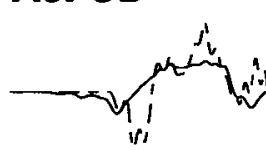

OSH NS<smiles>CC=CC=C(C)C</smiles>

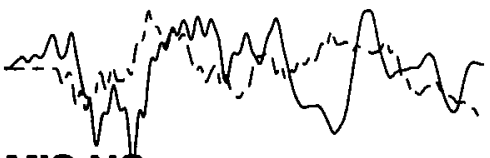

MIS NS

13.89

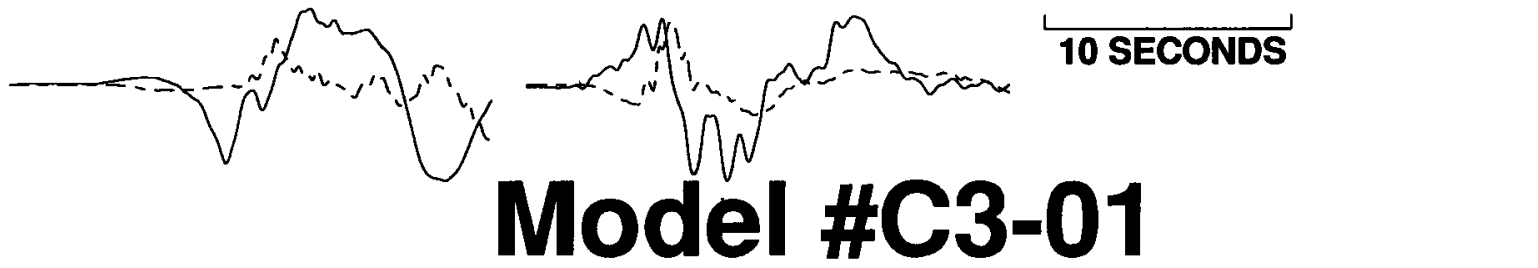

Fig. 15. A comparison between the observed and synthetic seismograms for model C3-01. Solid lines are the observations and brokens are the synthetics calculated from the final model of the crack inversion. 

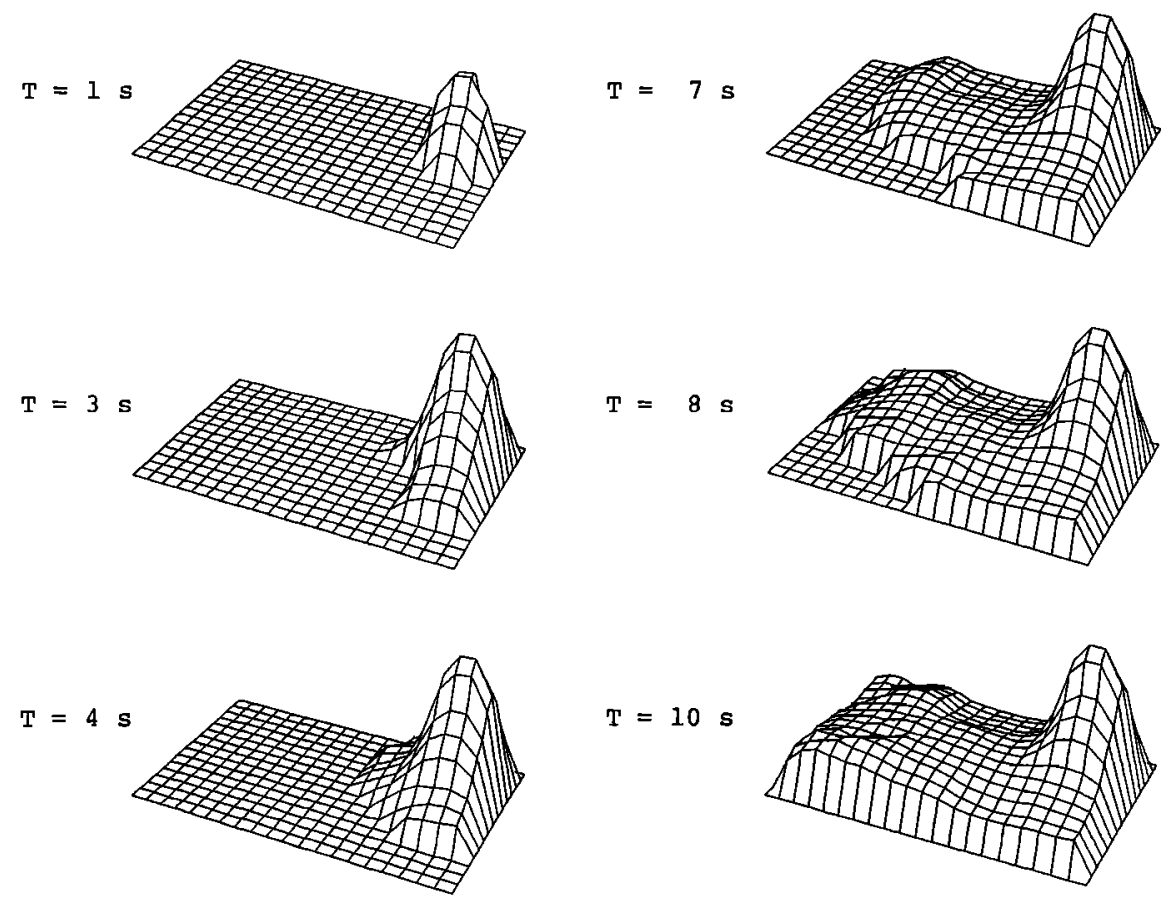

$\mathrm{T}=10 \mathrm{~s}$
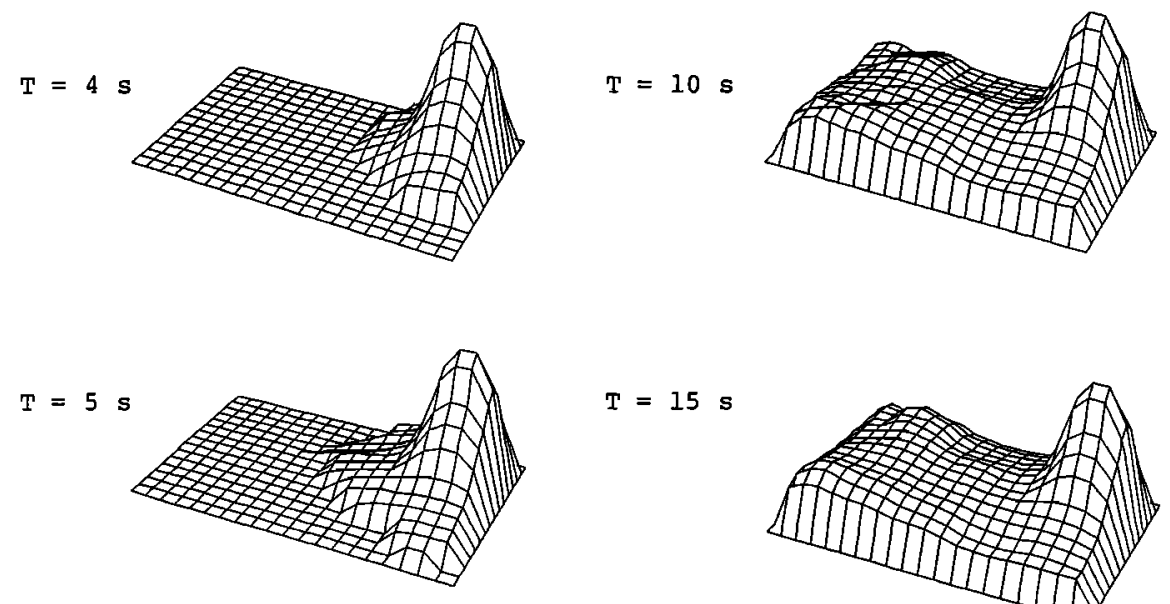

$\mathrm{T}=15 \mathrm{~s}$
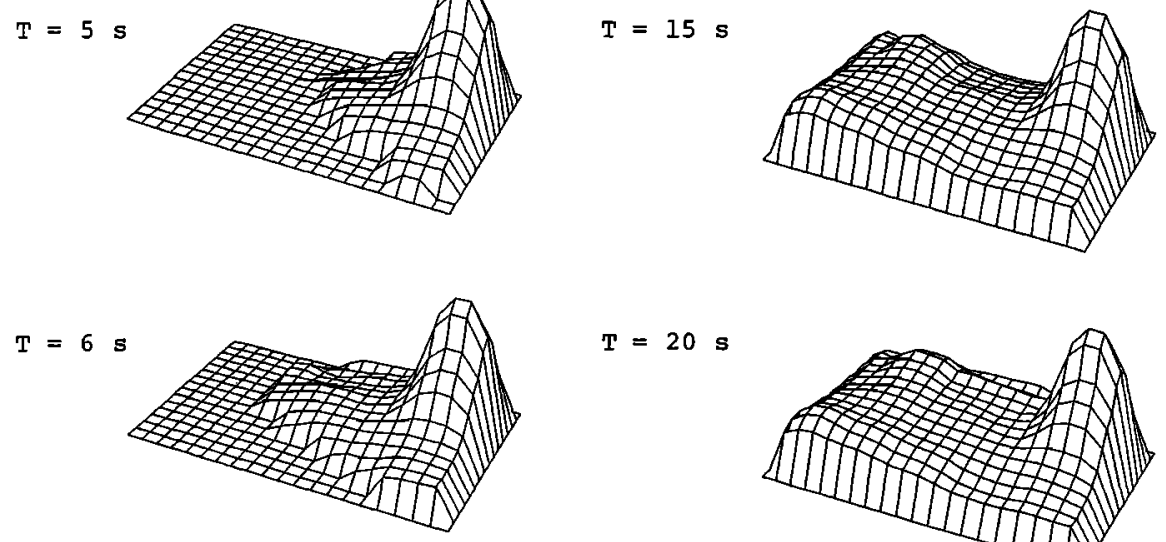

$\mathbf{T}=20 \mathrm{~s}$

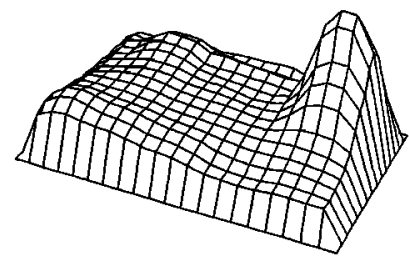

Dynamic Rupture ( Final Model )

Fig. 16. Time-sliced perspective view of displacement history and rupture propagation obtained by the final dynamic model fitting.

estimated errors of these parameters in the crack inversion may be less than $3 \%$ in view of the difference between the resultant dynamic slips and fault slips obtained from the waveform inversion. The results are summarized as follows:

1. The local dynamic stress drop exceeds $3.5 \mathrm{MPa}$ in the hypocentral zone in the northern section. It reaches $1.5 \mathrm{MPa}$ in shallow and deep zones in the southern section of the fault. However, it is generally smaller than 0.6 MPa elsewhere. Although there is a zone of very small stress drop located just south of the hypocentral zone, no negative stress drop has been detected.

2. The strength excess is found to be generally small except for the periphery of the hypocentral zone where it exceeds $1.3 \mathrm{MPa}$. The high strength zone may be correlated well to the zone of slow rupture velocity. The absolute values are quite uncertain as will be discussed later.
It should be mentioned, however, that the depth dependence of the stress drop and strength excess has not been identified, and their lateral variations are more dominant in the present earthquake.

Recent laboratory experiments indicate that frictional behavior of sliding surfaces are temperature dependent, and change from velocity weakening to velocity strengthening above $300 \sim 350 \mathrm{C}$ [e.g., Tse and Rice, 1986]. The velocity strengthening leads to negative stress drop, and it has been demonstrated theoretically [Mikumo, 1992] that the dynamic rupture of a large earthquake originating in the brittle zone can extend into the semibrittle zone with negative stress drop. Quin [1990] found a moderate amount of negative stress drop in the depth range of $11 \sim 13 \mathrm{~km}$ at the southern section of the 1979 Imperial Valley earthquake. This could be real and may be attributed to geothermal environments in 
a) Stress Drop

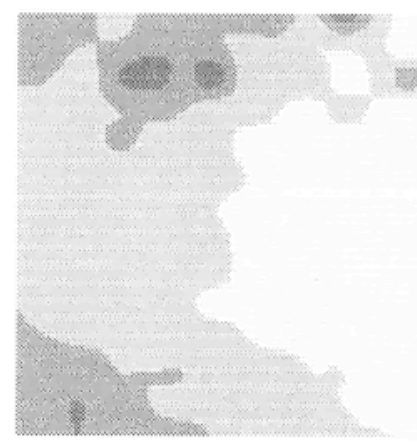

South

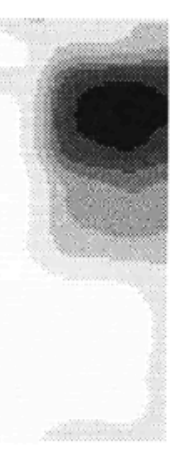

North

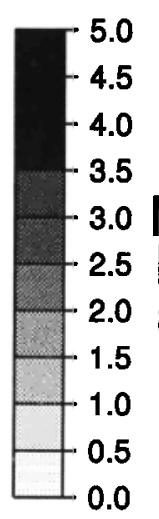

\section{b) Strength Excess}

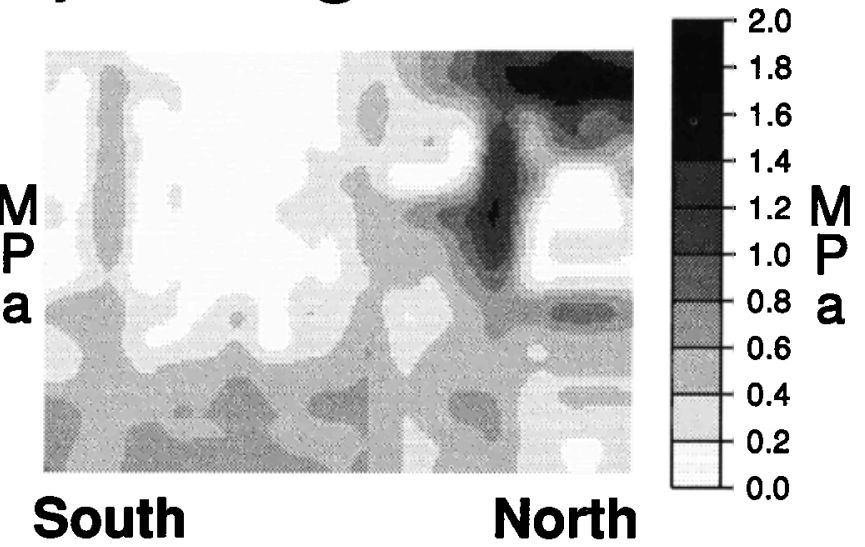

Fig. 17. The distributions of estimated $(a)$ stress drop and $(b)$ strength excess obtained by a crack inversion (model C3-01).

the lower crust in this region. However, this type of the negative stress drop has not been identified in the present case.

\section{Discussion}

The average stress over the grid immediately outside the tip is inversely proportional to the square root of the grid spacing [ $A k i$ and Richards, 1980]. The strength excess estimated here can be corrected taking into account the size of the breakdown zone just ahead of the crack tip. If we assume the size of the breakdown zone to be about $300 \sim 500$ $\mathrm{m}$ for a moderate-size earthquake [Aki, 1992], the maximum stress would be 1.4-1.7 times the estimated value for the grid spacing of $1 \mathrm{~km}$ used in the present analysis.

Although the absolute values of the strength excess are still quite uncertain, we may be able to discuss qualitatively a topographical feature of the fault strength and dynamic stress drop over the fault through a dimensionless stress ratio $S$, defined as the strength excess $\sigma_{s}-\sigma_{0}$ divided by the stress drop $\sigma_{0}-\sigma_{d}$ [Das and Aki, 1977].

It is noticed from Figure 18 that there are large $S$ zones from shallow to deep sections of the fault south of the hypocentral area, while small $S$ zones may be identified in the hypocentral zone and in the southern shallow section. Large $S$ values come from high strength excess and/or small stress drop and hence provide a stronger resistance to rupture propagation. This may be regarded as a barrier-type rupture zone. On the other hand, small $S$ values imply low strength excess and/or large stress drop, which may be taken as a break of asperity. It should be emphasized here that the two types of ruptures could occur on the fault during a single earthquake.

It is found, however, that there was more than $40 \mathrm{~cm}$ of slip displacement in the zone of large $S$ values. The relative intensity of barriers may be defined by this ratio. If this ratio has much higher values than obtained here, rupture would not occur there and might be arrested. This could be a strong barrier left unbroken. If, however, this ratio is not so high, the rupture occurs with a small slip as in this case. Small slip results mainly from low stress drop there.

It has been believed for long years and explicitly pointed out [Heaton, 1990] that the rise times calculated from

\section{Strength Excess / Stress Drop}

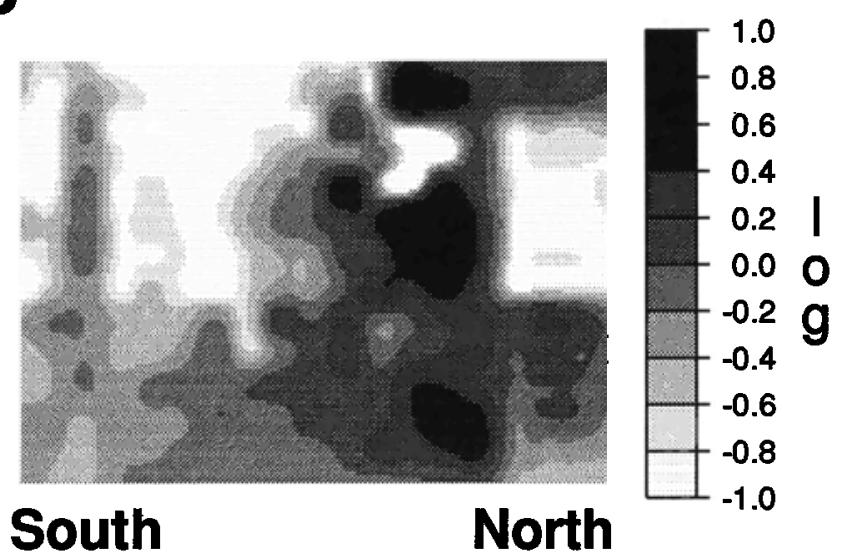

Fig. 18. The distribution of a dimensionless stress ratio $S$, which is obtained by the strength excess divided by the dynamic stress drop for (model C3-01). 


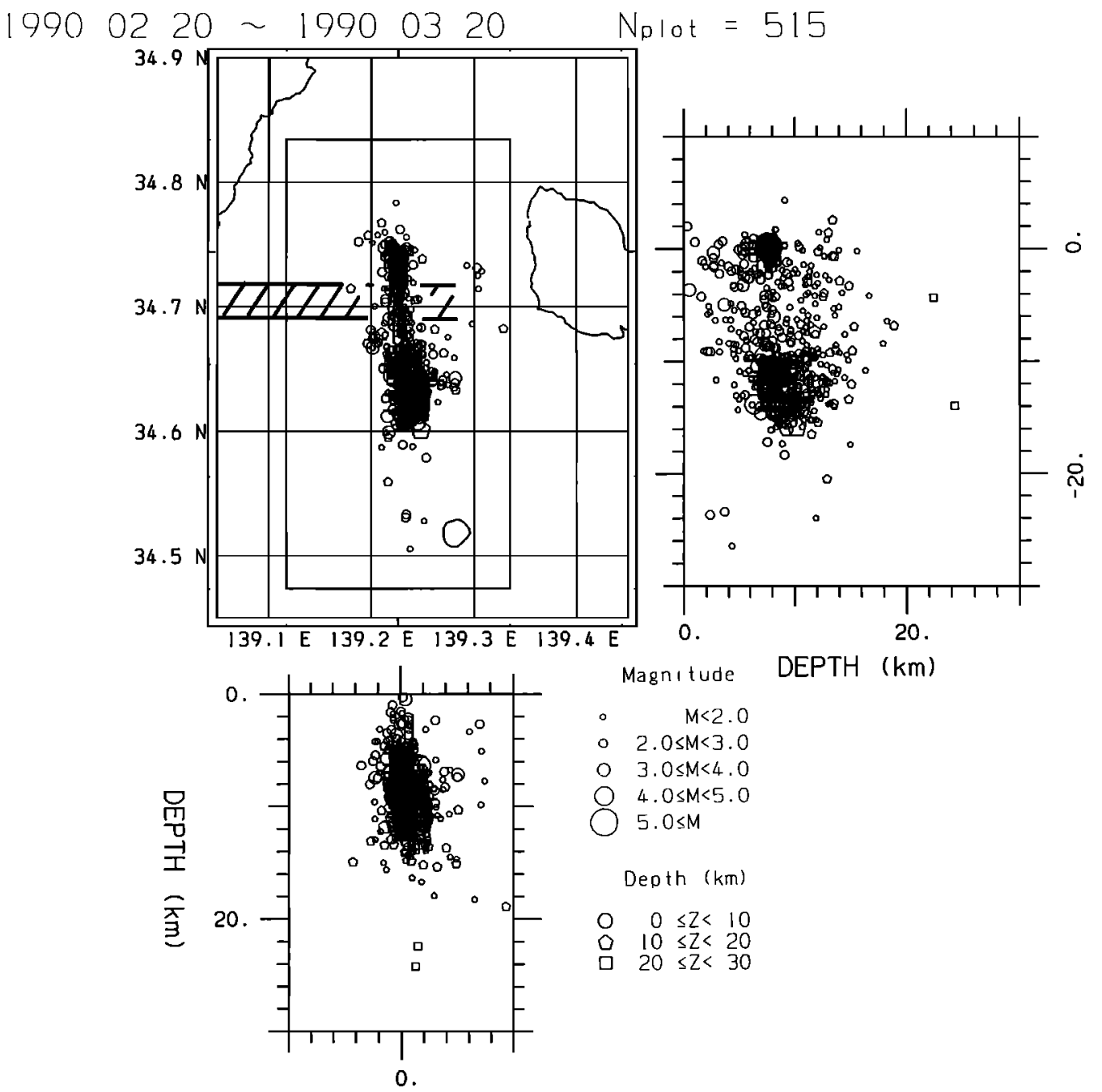

Fig. 19. The distribution of aftershocks for 1 month just after the main shock occurrence. The hatched area indicates the fault trace of the 1978 Izu-Oshima earthquake estimated from the aftershock distribution just after the main shock [Tsumura et al., 1978].

dynamic crack models are much longer than that from the kinematic modeling of waveform data. It has also been pointed out that the dynamic rupture model with the existence of a few barriers could yield shorter rise time to match the observed waveforms. In the present case, however, somewhat long rise times are necessary to explain the observation on the basis of the dynamic crack model. Although the major slip occurs in the first few seconds, slow slip with a duration of several seconds follows (Figure 9).

We compare these results with the aftershock activity. Figure 19 shows the epicentral distribution of aftershocks within 1 month after the main shock. It is found that the aftershock activity was very weak at the center of the fault. In this region the slip displacement is relatively small (Figures 12 and 16). From the results of the dynamic rupture analysis, a large $S$ value region with the high strength excess and low stress drop has been detected in this region. These enable us easily to interpret a possible relation between the main shock slip and the aftershock activity. This region seems to act as a barrier during the main shock faulting, corresponding to the crossing point of the 1978 Izu-Oshima earthquake [Shimazaki and Somerville, 1979; Kikuchi and
Sudo, 1984]. It may be suggested that the cause of the barrier during the 1990 Izu-Oshima earthquake could be the fault trace of the 1978 Izu-Oshima earthquake, that had shifted the preexistent north-south weak line and had made an offset.

\section{Conclusions}

We have developed an iterative inversion method that includes the three-dimensional dynamic crack calculation to obtain the stress-strength distribution over the fault. We have applied this method to the near-field strong motion array seismograms of the 1990 Izu-Oshima earthquake. Using the stress drop and strength excess information, we can identify the faulting type (barrier or asperity).

In the 1990 Izu-Oshima earthquake, near the initiation point of its rupture, the slip is large $(\sim 130 \mathrm{~cm})$ and the rise time is short, indicating high stress drop and low strength excess. Low $S$ value indicates an asperity-type faulting. While south of this region, low stress drop and high strength excess region is found, where the slip dislocation is small, rupture propagates slowly and incoherently, and rise time is long (>10 s). It is recognized as a barrier-type faulting. It is 
interesting that this barrier region corresponds to the intersection with the fault trace of the 1978 Izu-Oshima earthquake.

Acknowledgments. The authors appreciate the comments of the associate editor and two anonymous reviewers which helped to improve the original inversion scheme. They also appreciate John Nabelek for critical review of the final manuscript. A part of the waveform data was provided by the Japan Meteorological Agency. The discrete wavenumber synthesis program coded by Fumio Yamamizu was used. The calculation was done at the Data Processing Center, Kyoto University. A part of this work was done while one of the authors (E. F.) was on leave from National Research Institute for Earth Science and Disaster Prevention as a visiting researcher of the Laboratoire de Sismologie, Institut de Physique du Globe de Paris by the scholarship of the Science and Technology Agency, Japan.

\section{REFERENCES}

Aki, K., Higher-order of interrelations between seismogenic structures and earthquake processes, Tectonophysics, 211, 1-12, 1992.

Aki, K., and P. G. Richards, Quantitative Seismology: Theory and Methods, W. H. Freeman, New York, 1980.

Archuleta, R. J., A faulting model for the 1979 Imperial Valley earthquake, J. Geophys. Res., 89, 4559-4585, 1984.

Beroza, G. C., and P. Spudich, Linearized inversion for fault rupture behavior: Application to the 1984 Morgan Hill, California, earthquake, J. Geophys. Res., 83, 6275-6296, 1988.

Bouchon, M., A simple method to calculate Green's functions for elastic layered media, Bull. Seismol. Soc. Am., 71, 959-971, 1981.

Das, S., A numerical method for determination of source time functions for general three-dimensional rupture propagation, Geophys. J. R. Astron. Soc., 62, 591-604, 1980.

Das, S., and K. Aki, A numerical study of two dimensional spontaneous rupture propagation, Geophys. J. R. Astron. Soc., 50, 643-668, 1977.

Fukuyama, E., Analysis and interpretation of the heterogeneous rupture process: Application of the empirical Green's function method and nonlinear inversion technique to large earthquakes, Tectonophysics, 197, 1-17, 1991a.

Fukuyama, E., Inversion for the rupture details of the 1987 east Chiba earthquake, Japan, using a fault model based on the distribution of relocated aftershocks, J. Geophys. Res., 96, 8205$8217,1991 b$.

Fukuyama, E., and K. Irikura, Rupture process of the 1983 Japan Sea (Akita-Oki) earthquake using a waveform inversion method, Bull. Seismol. Soc. Am., 76, 1623-1649, 1986.

Hanks, T. C., and M. Wyss, The use of body-wave spectra in the determination of seismic-source parameters, Bull. Seismol. Soc. Am., 62, 561-589, 1972.

Hartzell, S. H., and T. H. Heaton, Inversion of strong ground motion and teleseismic waveform data for the fault rupture history of the 1979 Imperial Valley, California, earthquake, Bull. Seismol. Soc. Am., 73, 1553-1583, 1983.

Heaton, T. H., Evidence for and implication of self-healing pulses of slip in earthquake rupture, Phys. Earth Planet. Inter., 64, 1-20, 1990.

Ikami, A., Crustal structure in the Shizuoka district, central Japan as derived from seismic observations, J. Phys. Earth, 26, 299-331, 1978.
Irwin, G. R., Fracture mechanics, Handb. Phys., 79, 551-590, 1958. Kikuchi, M., and Y. Fukao, Iterative deconvolution of complex body waves from great earthquakes-The Tokachi-Oki earthquake of 1968, Phys. Earth Planet. Inter., 37, 235-248, 1985.

Kikuchi, M., and H. Kanamori, Inversion of complex body waves, III, Bull. Seismol. Soc. Am., 81, 2235-2350, 1991.

Kikuchi, M., and K. Sudo, Inversion of teleseismic $P$ waves of Izu-Oshima, Japan earthquake of January 14, 1978, J. Phys. Earth, 32, 161-171, 1984.

Mikumo, T., Dynamic fault rupture and stress recovery processes in continental crust under depth-dependent shear strength and frictional parameters, Tectonophysics, 211, 201-222, 1992.

Mikumo, T., and T. Miyatake, Dynamical rupture process on a three-dimensional fault with non-uniform frictions and near-field seismic waves, Geophys. J. R. Astron. Soc., 54, 417-438, 1978.

Mikumo, T., K. Hirahara, and T. Miyatake, Dynamical fault rupture processes in heterogeneous media, Tectonophysics, 144, 19-36, 1987.

Miyatake, T., Numerical simulations of earthquake source process by a three-dimensional crack model, part I, Rupture process, $J$. Phys. Earth, 28, 565-598, 1980.

Miyatake, T., Reconstruction of dynamic rupture process of an earthquake with constraints of kinematic parameters, Geophys. Res. Lett., 19, 349-352, 1992.

Quin, H., Dynamic stress drop and rupture dynamics of the October 15, 1979 Imperial Valley, California, earthquake, Tectonophysics, 175, 93-117, 1990.

Ruff, L., and H. Kanamori, The rupture process and asperity distribution of three great earthquakes from long-period diffracted $P$-waves, Phys. Earth Planet. Inter., 31, 202-230, 1983.

Shimazaki, K., and P. Somerville, Static and dynamic parameters of the Izu-Oshima, Japan earthquake of January 14, 1978, Bull. Seismol. Soc. Am., 69, 1343-1378, 1979.

Takeo, M., An inversion method to analyse the rupture process of earthquakes using near-field seismograms, Bull. Seismol. Soc. Am., 77, 490-513, 1987.

Takeo, M., Rupture process of the 1980 Izu-Hanto-Toho-Oki earthquake deduced from strong motion seismograms, Bull. Seismol. Soc. Am., 78, 1074-1091, 1988.

Takeo, M., and N. Mikami, Inversion of strong motion seismograms for the source process of the Naganoken-Seibu earthquake of 1984, Tectonophysics, 144, 271-285, 1987.

Tse, S. T., and J. R. Rice, Crustal earthquake instability in relation to the depth relation of frictional slip properties, J. Geophys. Res., 91, 9452-9472, 1986.

Tsumura, K., I. Karakama, I. Ogino, and M. Takahashi, Seismic activities before and after the Izu-Oshima-Kinkai earthquake of 1978, Bull. Earthquake Res. Inst., 53, 675-706, 1978.

Yao, Z. X., and D. G. Harkrider, A generalized reflectiontransmission coefficient matrix and discrete wavenumber method for synthetic seismograms, Bull. Seismol. Soc. Am., 73, 1685$1699,1983$.

E. Fukuyama, National Research Institute for Earth Science and Disaster Prevention, 3-1 Tennodai, Tsukuba, Ibaraki, 305, Japan.

T. Mikumo, Centro Nacional de Prevencion de Disastres, México 04360 D. F., México.

(Received October 21, 1991; revised September 17, 1992; accepted October 12,1992.) 